\title{
Thoracic Renal Artery
}

\author{
Umberto G. Rossi, MD, EBIR ${ }^{1}$ Gian Andrea Rollandi, MD² \\ 1 Department of Diagnostic Imaging, Interventional Radiology Unit, \\ Ente Ospedali Galliera Hospital, Genova, Italy \\ 2 Department of Diagnostic Imaging, Radiology Unit, Ente Ospedali \\ Address for correspondence Umberto G. Rossi, MD, EBIR, \\ Department of Diagnostic Imaging-Interventional Radiology Unit, \\ Galliera Hospital, Genova, Italy \\ Ente Ospedali Galliera Hospital, Mura delle Cappuccine, 14-16128, Genova, \\ Italy (e-mail: urossi76@hotmail.com; umberto.rossi@galliera.it).
}

AORTA 2019;7:96-97.

\begin{abstract}
Keywords

- renal artery

- ectopic renal artery

- computed tomography

- vascular variant

- aorta surgical intervention.

A 69-year-old man, with abdominal aortic aneurysm, underwent multidetector computed tomographic (MD-CT) angiography as a diagnostic investigation for possible endovascular aneurysm repair (EVAR). The examination confirmed abdominal aortic aneurysm with a diameter of $5.1 \mathrm{~cm}$. In the scans passing through the lower thorax, a right single ectopic renal artery originating at the level of T12 vertebra was found ( $\mathbf{- F i g . ~ 1 A , ~ B ) . ~ I n ~ a d d i t i o n , ~ t h e ~ r i g h t ~}$ single ectopic renal artery was associated with a normal position of the ipsilateral kidney. This anatomical variant did not affect or preclude the subsequent EVAR.
\end{abstract}

We report a case of right renal artery originating from the thoracic aorta with normal position of the right kidney. Although this anomaly is rare, vascular, thoracic, and urological surgeons should be aware about this vascular variant before planning their
Knowledge of variations in kidney vascular anatomy, in terms of number and origin, is important for patients who are candidates for EVAR, renal transplantation, renal surgery, and/or endovascular treatment. ${ }^{1-4}$ This is crucial to prevent possible complications or errors.

MD-CT angiography is now the first-line diagnostic method to detect vascular anatomy, including renal anatomy. ${ }^{1}$ There are several reports of ectopic renal arteries in the literature. But, to our knowledge, this is only the seventh report of single ectopic renal artery originating in the thorax with normal kidney position. ${ }^{2,5}$ received

February 27, 2018

accepted after revision

May 9, 2019
DOI https://doi.org/

10.1055/s-0039-1693987.

ISSN 2325-4637.
Copyright $\odot 2019$ by Thieme Medical

Publishers, Inc., 333 Seventh Avenue, New York, NY 10001, USA. Tel: +1(212) 584-4662.
License terms 

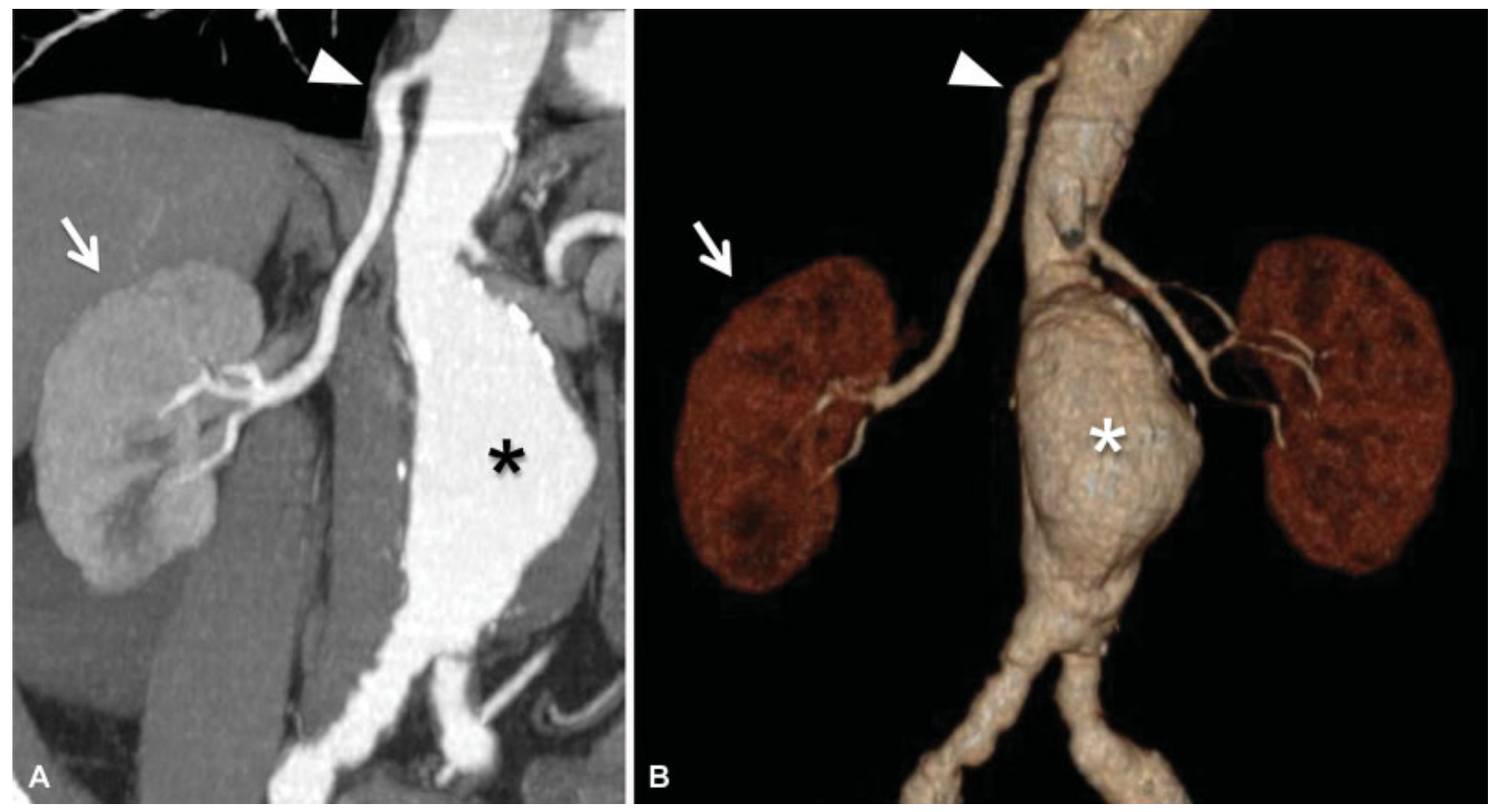

Fig. 1 (A, B) Multidetector computed tomographic angiography with (A) coronal maximum intensity projection and (B) volume rendering reconstruction technique that demonstrates the presence of the abdominal aortic aneurysm $\left(^{*}\right)$ and the normal position of the right kidney (arrow) with a single ectopic renal artery originating from the thoracic aorta (arrowhead).

Funding

This research was funded solely through institutional sources.

\section{Conflict of Interest}

The authors declare no conflict of interest related to this article.

\section{Acknowledgment}

None.

\section{References}

1 Rossi UG, Romano M, Ferro C. Seven renal arteries. Clin Anat 2006; 19(07):632-633
2 Delasotta LA, Olivieri B, Malik A, Nguyen C, Bhatia V, Burke W. Thoracic renal artery: a rare variant. A case study and literature review. Surg Radiol Anat 2015;37(05):561-564

3 Rossi UG, Rollandi GA, Dallatana R, Cariati M. Mechanical aspiration thrombectomy in the treatment of acute intrastent renal artery thrombosis. Cardiovasc Revasc Med 2019;20(04): 344-346

4 Bianchini Massoni C, Azzarone M, Barbarisi D, Perini P, Freyrie A. Ruptured abdominal aortic aneurysm in a patient with congenital fused pelvic kidney: a case report of emergency endovascular treatment. Aorta (Stamford) 2018;6(01):21-27

5 Ishida M, Namiki Y, Watanabe M. Thoracic renal artery: a rare case of the renal artery originating from the thoracic aorta and literature review. Anat Sci Int 2016;91(02):211-214 